\title{
Alcohol behaviour and consequences during COVID-19. A research in Italy on a sample of university students.
}

Nicola Malizia ( $\sim$ nicola.malizia@unikore.it )

Università degli Studi di Enna Kore

\section{Research Article}

Keywords: AUDIT, Covid-19, Deviant behaviour, Psychological problems, University student.

Posted Date: May 5th, 2021

DOI: https://doi.org/10.21203/rs.3.rs-442632/v1

License: (c) (i) This work is licensed under a Creative Commons Attribution 4.0 International License.

Read Full License 


\section{Abstract}

Background This study explored the drinking behaviour of a sample of 351 Italian university students during COVID-19 in the year 2020, in order to understand whether restrictions, including social isolation imposed to avoid contagion, led to an increase or decrease in alcohol consumption at the individual level. The Alcohol Use Disorders Identification Test (AUDIT) and an online self-report questionnaire were used for this purpose. The research also investigated the knowledge of university students regarding the risks associated with alcohol use and the consequences on university performance, as well as on a personal, psychological, social and family level. Finally, the relationship between boredom and alcoholism during the pandemic phase was studied.

Results Response rates were $100 \%(n=351)$. With regard to the "absences or tardiness in the virtual university class" for alcoholic conduct, it was found that only a small number of students have used alcohol (with reference to the AUDIT) and became dependent during the Covid-19 pandemic in the year 2020; with regard to the "low personal performance at university" related to alcohol (with reference to the AUDIT), there is also in this case a small number of students who use alcohol in the pandemic period have found a low performance in university studies. The research has investigated, moreover, the appearance of psychological problems as a result of alcoholic conduct (AUDIT) in the sample of reference, concerning conflicts with parents, depression, anxiety, emotional oscillations, irritability and low tolerance, as well as, personal problems of a social nature. The results show that in college students, alcohol has no significant consequences. Finally, the relationship between "boredom and alcohol behavior" (AUDIT) during the pandemic phase of the year 2020 was investigated: the results show that boredom was felt by a high number of university males and females and a significant number used alcoholic substances, even becoming addicted, and considering alcohol as a real refuge.

Conclusion The research carried out has a twofold objective: 1) to evaluate the alcoholic behavior during the pandemic phase of Covid-19 by a sample of university students $(\mathrm{N}=351) ; 2)$ to understand the knowledge of the risks related to alcoholic behavior at a personal, family, sociological and psychological level, in a more general and non-pandemic context. The research has some limitations due to the smallness of the sample, although the results obtained could be useful as a starting point for future research, with larger samples and oriented especially to problematic and non-problematic alcohol behavior. It would certainly be necessary a vast and effective worldwide campaign of information and awareness on the risks of alcohol, dedicating, especially in this period, even an hour of training in virtual university classrooms, to make people understand how alcoholic behavior is potentially harmful both during emergencies such as a pandemic, and in convivial and aggregation contexts that characterize the modern life of young people. Effectively informing people about the risks of alcohol responds to a need for prevention, erasing the belief that drinking is not bad for you.

\section{Introduction}


The use of alcohol represents, according to sociological literature, a deviant act, and is normally perceived as the result of an individual state of social disorganisation, a lack of integration of the subject with the values of society, or temporary situations of stress (Censi et al. 2019). The use of alcoholic substances, especially in young people, becomes a social phenomenon that has significant connections with cultural, social, family and individual origins (Calamai 2018). The COVID-19 pandemic has had a major impact on individuals, families and communities worldwide. Psychologists believe that individual reactions to the pandemic are comparable to a traumatic event, war or disaster (Panagiotidis et al. 2020), and take positive and negative forms of coping in daily life. Recent studies have shown a trend of increasing alcohol use during COVID-19 as a psychological comfort substance (Ornell et al. 2020) and a general worldwide increase in alcohol sales from March 2020 (Martin 2020). The increase in alcohol use as individual self-care is a temporary solution, but not a long-term one (SAMSHA 2020). Intra-family conflicts, depression, anxiety, stress, emotional swings, irritability and low tolerance are also related to increased alcohol use (Lyers et al. 2020; Lin et al. 2020; Galea et al. 2020; Sola et al. 2019; Bränström and Pachankis 2018; Hassel et al. 2013). The consequences of the COVID-19 pandemic on the psychological health and well-being of individuals have been extensively investigated (Walker et al. 2020). COVID-19related anxiety, in particular, represents one of the most commonly experienced sufferings during the pandemic. Recent research has shown that people with high levels of coronavirus anxiety have exhibited despair and suicidal ideation (Mclntyre and Lee 2020). A recent survey in China showed that $53.8 \%$ of participants had a moderate to severe psychological impact with the epidemic: $17.4 \%$ experienced moderate to severe depressive symptoms and $28.8 \%$ moderate to severe anxiety symptoms ( $\mathrm{Li}$ et al. 2020). In addition, another study in China during the pandemic showed that $35 \%$ of participants suffered from psychological distress (Qiu et al. 2020). It should be noted that alcohol consumption makes a person more vulnerable to disease and in particular to COVID-19 infection and no level of alcohol consumption improves health (Burton \& Sheron 2018). Alcohol abuse is also a risk factor for pneumonia and other lung infections and the development of acute respiratory distress syndrome (ARDS), which is a major complication of Covid-19. The inclusion of a health goal to strengthen the prevention and treatment of substance use disorders in the 2030 Sustainable Development Goals (SDG 2030) agenda is an important recognition of the negative effects of alcohol use. Although over the years, many studies have estimated that a high number of students consume alcohol during their university life, few studies have focused on the social, family, personal and psychological factors that may contribute to or facilitate this deviant behaviour (Beck et al. 2009). According to Scott et al. (2020), alcohol use is associated with problems that vary by age; impairments are greater for young adults (18 to 24 years) than for older adults (25 years and older. Recent studies show that frequent alcohol use is prevalent in younger populations (National Institute of Drug Abuse (NIDA) 2019). Although the relationship between alcohol consumption and social, ecological and cultural conditions has been studied in the past, there is now a need to investigate new mechanisms that drive young people to use alcohol: the ongoing pandemic can be a field of study and research to understand how individuals react or why they commit deviant acts. This research also explored the relationship between boredom and alcohol, with reference to the pandemic. When boredom determines the passage to the deviant act, it is necessary to analyze the inner (personal) and external (social factors) forces that have driven and determined this behavior. In a modern context 
such as the pandemic, boredom, linked to the condition of social isolation especially of young people, can turn into different reactions, such as the voluntary abandonment of institutional paths (university and related studies), the lack of acceptance of the current social configuration, the need to reach new goals or to take risks, the use of alcohol or drugs to defeat social loneliness (Orgilès et al. 2020). Matza (1964), argues that deviant behavior is closely related to the will and self-determination of the subject and not to social or environmental conditioning. Over time, many interpretations of the term "boredom" have been provided: according to Barbalet (1999) "it represents an emotional state that arises from an individual's lack of meaning in a situation or activity, which tends to turn into a feeling of discomfort and irritation and must be replaced with something exciting"; according to Brisset \& Snow (1993), "boredom can also be related to a lack of involvement in everyday events and the lack of momentum may represent factors that encourage the subject to engage in deviant behavior. If boredom and a lack of personal skills or leisure opportunities prevail in leisure time, some youth may, according to Iso-Ahola and Crowley (1991), engage in deviant behaviors such as drug use, alcohol, and gambling. Youth boredom could also be the result of a lack of knowledge or material inability to access the activities that constitute true leisure or entertainment (Stebbins, 2002). According to Thomas (1923), failure to meet basic needs, or leading an interest-free life, could lead youth, but especially young girls, to engage in deviant behavior (Volkart 1951). Zuckerman's Sensation Seeking Theory deals specifically with the concept of boredom and new sensation seeking: Using Eysenck's (1978) theory of extroversion, which incorporates sociability and impulsivity, Zuckerman defines "sensation seeking" as a type of "uninhibited, nonconforming, impulsive, dominant" extroversion composed of such distinct factors as thrill seeking, adventure seeking, experience seeking, disinhibition, and susceptibility to boredom (Zuckerman, Eysenck, and Eysenck 1978).

Disinhibitors or "extroverted sensation seekers" will seek sensations through social stimulation and disinhibitory behavior (usually associated with the use of alcohol and drugs), while individuals who are prone to boredom will avoid boring people and repetitive activities (Zuckerman, Eysenck and Eysenck 1978). With regard to the relationship (not during the pandemic) between college students and alcohol use, it is worth noting a U.S. study on the knowledge of and attitudes toward the alcohol rules in effect on college campuses which shows that the majority of new students are aware of the restrictions, but that less than half are willing to accept them (Cao et al. 2020). Finally, one cannot forget the contributions of scholars who define contemporary society as a risk society and individualized (Giddens 1991). Sargent et al. (2020) also argue that a culturally marked society drives individuals to use psychoactive substances (including alcohol) that promise well-being. The relationship between pandemic (forced social isolation) and alcohol has contributed, especially in the year 2020 to change many theoretical approaches on the so-called "styles of drinking": The "convivial style", characterized by the search for the pleasure of being together, and the "homogenizing style of group" in which alcohol plays the role of homologation of the individual subject to the group have disappeared, strengthening the tendency to drink alone at home (Corbin et al. 2020).

\section{Method}


Data were taken from a study of 351 Italian university students with the aim of understanding alcohol use during the Covid-19 pandemic in the year 2020 and identifying the consequences. To this end, the Alcohol Use Disorders Identification Test (AUDIT) and a self-report questionnaire were used as instruments to assess associated problems. The AUDIT includes questions on the consequences of alcohol consumption, together with questions on quantity and frequency of intake. It consists of 10 items, with 5 possible answers, with a score from 0 to 4 , except items 9 and 10, which only have a score of 0,2 , 4. The result is obtained by summing the scores of the domains: risk-free consumption, dependence and hazardous consumption. The AUDIT and the self-report questionnaire were administered at the end of the online lessons (distance learning). Each participant was allocated a time limit of 30 minutes. The questionnaire covered a wide range of topics including: a) individual and personal data (single, married, engaged, separated); b) problems with participation in university activities and low performance (correlated with AUDIT); c) psychological problems, such as depression, anxiety, emotional swings, quarrels with parents, irritability and low tolerance (correlated with AUDIT); d) social problems (correlated with AUDIT) concerning loss of friends, loss of partner, voluntary estrangement from family. Finally, the incidence of boredom and alcoholic behaviour as a consequence of social isolation imposed to prevent COVID-19 infections was explored. Data were collected between March 2020 and December 2020. Data were processed between January and February 2021. Informed consent was obtained for participation in all phases of this study; participation was completely free and voluntary; no reward or compensation was obtained by the student. The research method and the questionnaire administered online were reviewed and approved by the University of Enna "Kore" - Italy. All information was treated with the utmost confidentiality. The main aspect that was highlighted as particularly important for the validity of the questionnaire was the students' trust in the anonymity of their answers. The description of the results was based on descriptive statistical techniques and tools, using Mathlab 2015b, depending on the type of variable. Our target population consisted of Kore University students aged 18 years and older, residing in households in EU member states. Although the age range of the university population varies widely, the vast majority of university students (87.13\%) are between the ages of 18 and 26 ; therefore, we focused our analysis on this age group.

Tab. 1 (Summary Fig. 3) 


\begin{tabular}{|c|c|c|c|c|}
\hline Tipology and P value & $\begin{array}{l}\text { Risk-free } \\
\text { consumption }\end{array}$ & $\begin{array}{l}\text { Hazardous } \\
\text { consumption }\end{array}$ & Dependence & \\
\hline $\begin{array}{l}\text { Conflict with parents } \\
(P \text { value } \leq 0.001)\end{array}$ & $\begin{array}{l}19 \text { (yes); } 176 \text { (no) } \\
\text { Total=195 }\end{array}$ & $\begin{array}{l}28 \text { (yes); } 82 \text { (no) } \\
\text { Total=110 }\end{array}$ & $\begin{array}{l}23 \text { (yes); } 23 \\
\text { (no) } \\
\text { Total }=46\end{array}$ & $\begin{array}{l}\text { Total: } \\
351\end{array}$ \\
\hline $\begin{array}{l}\text { Depression } \\
(\mathrm{P} \text { value } \leq 0.001)\end{array}$ & $\begin{array}{l}19 \text { (yes); } 176 \text { (no) } \\
\text { Total=195 }\end{array}$ & $\begin{array}{l}38 \text { (yes); } 72 \text { (no) } \\
\text { Total=110 }\end{array}$ & $\begin{array}{l}22 \text { (yes); } 24 \\
\text { (no) } \\
\text { Total }=46\end{array}$ & $\begin{array}{l}\text { Total: } \\
351\end{array}$ \\
\hline $\begin{array}{l}\text { Anxiety } \\
(\mathrm{P} \text { value } \leq 0.001)\end{array}$ & $\begin{array}{l}17 \text { (yes); } 178 \text { (no) } \\
\text { Total=195 }\end{array}$ & $\begin{array}{l}41 \text { (yes); } 69 \text { (no) } \\
\text { Total=110 }\end{array}$ & $\begin{array}{l}23 \text { (yes); } 23 \\
\text { (no) } \\
\text { Total }=46\end{array}$ & $\begin{array}{l}\text { Total: } \\
351\end{array}$ \\
\hline $\begin{array}{l}\text { Emocional oscillation } \\
\text { (P value } \leq 0.001)\end{array}$ & $\begin{array}{l}38 \text { (yes); } 157 \text { (no) } \\
\text { Total=195 }\end{array}$ & $\begin{array}{l}55 \text { (yes); 55(no) } \\
\text { Total=110 }\end{array}$ & $\begin{array}{l}20 \text { (yes); } 26 \\
\text { (no) } \\
\text { Total }=46\end{array}$ & $\begin{array}{l}\text { Total: } \\
351\end{array}$ \\
\hline $\begin{array}{ll}\text { Irritability, } & \text { low } \\
\text { tolerance } & \\
(\mathrm{P} \text { value } \leq 0.001) ; & \\
\end{array}$ & $\begin{array}{l}17 \text { (yes); } 178 \text { (no) } \\
\text { Total=195 }\end{array}$ & $\begin{array}{l}24 \text { (yes); 86(no) } \\
\text { Total=110 }\end{array}$ & $\begin{array}{l}17 \text { (yes); } 29 \\
\text { (no) } \\
\text { Total }=46\end{array}$ & $\begin{array}{l}\text { Total: } \\
351\end{array}$ \\
\hline
\end{tabular}

Tab. 2 (Summary Fig.4)

\begin{tabular}{|c|c|c|c|c|}
\hline Tipology and $\mathrm{P}$ value & $\begin{array}{l}\text { Risk-free } \\
\text { consumption }\end{array}$ & $\begin{array}{l}\text { Hazardous } \\
\text { consumption }\end{array}$ & Dependence & \\
\hline $\begin{array}{l}\text { Loss of friends } \\
(P \text { value } \leq 0.030)\end{array}$ & $\begin{array}{l}11 \text { (yes); } 184 \text { (no) } \\
\text { Total=195 }\end{array}$ & $\begin{array}{l}11 \text { (yes); } 99 \text { (no) } \\
\text { Total=110 }\end{array}$ & $\begin{array}{l}8 \text { (yes); } 38 \\
\text { (no) } \\
\text { Total }=46\end{array}$ & $\begin{array}{l}\text { Total: } \\
351\end{array}$ \\
\hline $\begin{array}{l}\text { Loss of partrners } \\
\text { ( } \mathrm{P} \text { value } \leq 0.001 \text { ) }\end{array}$ & $\begin{array}{l}12 \text { (yes); } 183 \text { (no) } \\
\text { Total=195 }\end{array}$ & $\begin{array}{l}28 \text { (yes); } 82 \text { (no) } \\
\text { Total=110 }\end{array}$ & $\begin{array}{l}18 \text { (yes); } 28 \\
\text { (no) } \\
\text { Total }=46\end{array}$ & $\begin{array}{l}\text { Total: } \\
351\end{array}$ \\
\hline $\begin{array}{l}\text { Voluntary departure from } \\
\text { family } \\
\text { (P value } \leq 0.001) \text {; }\end{array}$ & $\begin{array}{l}19 \text { (yes); } 176 \text { (no) } \\
\text { Total=195 }\end{array}$ & $\begin{array}{l}28 \text { (yes); } 82 \text { (no) } \\
\text { Total=110 }\end{array}$ & $\begin{array}{l}23 \text { (yes); } 23 \\
\text { (no) } \\
\text { Total }=46\end{array}$ & $\begin{array}{l}\text { Total: } \\
351\end{array}$ \\
\hline
\end{tabular}

\section{Results}

Response rates were $100 \%(n=351)$. Informed consent was obtained. Students were instructed online and verbally (as described on the first page of the questionnaire sent out for the survey) that they were not to enter their names or other identifying marks on the questionnaire. All analyses were conducted using Mathlab 2015b. The age range (Fig. 1 ) varied as follows: for females from $18-25$ years $(184=52.43 \%)$, for males from $18-25(141=40.17 \%)$, and for others over 25 years $(26=7.40 \%)$. Their personal situation was also investigated: single were $127(36.20 \%)$; married were 1 (0.28\%); those in a relationship were 221 (62.96\%); separated were 2 (0.56\%). The research investigated: 1$)$ absences or tardiness in the virtual classroom (Fig. 2) (P value $\leq 0.001)$ for alcohol-related problems (AUDIT): (a) regarding 'risk-free drinking', the results showed that out of a total of 195 students (out of 351), 24 responded that they used alcohol in a risky way with consequences related to tardiness or absences in the virtual classroom; while 171 responded that they drank without risk not accumulating tardiness or absences to classes; (b) regarding "hazardous drinking," 41 students responded to this section stating that they had used alcohol 
in a hazardous manner and 69 responded that they had not used alcohol in a hazardous manner; (c) regarding "alcohol dependence," 31 students (out of 46) responded to this section stating that they were dependent, while 15 responded that they were not dependent; 2) low college performance of the student sample (351) in correlation with AUDIT ( $P$ value $\leq 0$. 001): of 195 students: a) 5 correlated low performance with risk-free alcohol use; 190 did not correlate low university performance with risk-free alcohol use; b) regarding hazardous alcohol use, 18 responded "yes" correlating this behavior with low personal university performance, 92 responded "no"; c) regarding "alcohol dependence," 24 students (of 46) stated that alcohol dependence was correlated with low university performance, while 22 denied this correlation. Another objective of the survey concerned the occurrence of psychological problems (Fig. 3 summary Tab. 1) in correlation with AUDIT (consumption without risk; dangerous consumption; dependence), concerning: 1) conflicts with parents; 2) depression; 3) anxiety; 4) emotional oscillations; 5) irritability and low tolerance. The analysis of the results shows that the psychological problems that emerge do not seem to be correlated, according to the answers given by the sample of university students (351), with the use of alcoholic substances (AUDIT). Table 2 (summary Fig. 4) shows the correlations between alcohol (AUDIT) and social and family problems for the items: a) loss of friend; loss of partner; voluntary estrangement from family. The data again showed a clear preponderance of "no" versus "yes" items. The last phase of the research looked at the correlation by gender (male and female) between boredom, (dictated by social and friend isolation to avoid Covid-19 contagions in the year 2020) and the AUDIT system (Tab. 3 - summary Fig. 5). Analysis of the results showed that: a) boredom was experienced by 189 (males) and 124 (females); b) 113 (males) and 57 (females) took alcohol without risk; c) 85 (males) and 39 (females) were reckless alcohol users; d) 55 (males) and 38 (females) became alcohol dependent during the pandemic period in the year 2020 due to boredom.

\section{Declarations}

\section{Declarations}

\section{1) ethical approval and consent to participate:}

2) The research was performed in accordance with the Declaration of Helsinki. I confirm that all experimental protocols were approved by the Ethics Committee of the University of Enna "Kore" - Italy. I confirm that written informed consent was obtained from all subjects.

\section{3) Consent for publication:}

4) Igive my consent for information about myself to be published in BMC Public Health ISSN 1471-2458 the article author of the article entitled: "Alcohol behaviour and consequences during COVID-19. A research in Italy on a sample of university students". No participant information was provided in the article, therefore, the item "consent to publication by participants "is not applicable". I understand that the text and any pictures or videos published in the article will be freely available on the internet and may be seen by the general public. The pictures, videos and text may also appear on other websites or in print, 
may be translated into other languages or used for commercial purposes. I have been offered the opportunity to read the manuscript.

\section{Declarations}

\section{6) Competing interests:}

7) The author Prof. Nicola Malizia declares not to have interests in conflict.

\section{Funding:}

Personal funds of Professor Nicola Malizia.

\section{Acknowledgements}

I would like to thank the research group on "deviance and crime" of the University of Enna "Kore" - Italy, consisting of young researchers and graduates, for the commitment shown in all phases of research and without which it would not have been possible to achieve the results presented.

\section{Conclusion}

The COVID-19 pandemic, in addition to having changed the lifestyles, habits and behaviors of populations around the world, has certainly opened up new fields of investigation and research, especially with regard to the consequences of social isolation on the individual imposed by the governments of nations to avoid contagion. The present research, with the limitations it presents, investigated the correlation between COVID-19 and AUDIT (Alcohol Use Disorders Identification Test) in a sample of Italian university students, in order to understand, in essence, if personal alcohol consumption can increase or decrease due to the restrictions imposed for an exceptional event such as the pandemic, comparing it with the general convivial style (such as being together and drinking alcohol, typical of young people in a non-pandemic condition). Taking into consideration in this research the age of reference, the condition of university student, the profit in studies, the consequences and the risks on a personal, social and family level, it was useful to understand, above all on a psychological, personal and social level, if the risks linked to alcohol, in general, are known by young people, or if alcohol can be considered a simple "refuge" from the pandemic and if boredom (the effect of the imposed social distancing) can trigger alcoholic behavior. Many questions remain about the correlation between COVID-19 and alcohol, but more importantly, there is a need to think about the tools to use and motivational and personalized interventions to reduce deviant behaviors in complex situations such as a pandemic. There is certainly a need for a broad and effective awareness campaign aimed especially at young people about the risks associated with alcoholic behavior. Effectively informing people about the risks of alcohol responds to a need for prevention, erasing the belief that drinking is not bad for you. For university students, it would be 
enough, before the start of classes, to devote even one hour to explain (online or in presence) in preventive terms, what could be the effects of social isolation from pandemic and how to protect themselves, avoiding deviant behaviors, such as alcohol, etc.. Future studies should also investigate problematic and nonproblematic alcohol use both during the pandemic and during the resumption of normal life (after a pandemic). This survey is stat aimed at students at only one university, so in terms of limitation, the results may not be generalizable to students at other larger/smaller, public/private universities. Therefore, these results should be considered preliminary until more robust research, with a larger sample and variables, could confirm the estimates obtained or produce new survey results.

\section{Declarations}

\section{Acknowledgements}

I would like to thank the research group on "deviance and crime" of the University of Enna "Kore" - Italy, consisting of young researchers and graduates, for the commitment shown in all phases of research and without which it would not have been possible to achieve the results presented.

\section{Prof. Nicola Malizia (NM)}

The Prof. Nicola Malizia (initials of Author NM), author of the article entitled: "Alcohol behaviour and consequences during COVID-19. A research in Italy on a sample of university students", declares under his personal responsibility, the following:

1. ethical approval and consent to participate: The research was performed in accordance with the Declaration of Helsinki. I confirm that all experimental protocols were approved by the Ethics Committee of the University of Enna "Kore" - Italy. I confirm that written informed consent was obtained from all subjects.

2. Consent for publication: I give my consent for information about myself to be published in BMC Public Health ISSN 1471-2458 the article author of the article entitled: "Alcohol behaviour and consequences during COVID-19. A research in Italy on a sample of university students". No participant information was provided in the article, therefore, the item "consent to publication by participants "is not applicable". I understand that the text and any pictures or videos published in the article will be freely available on the internet and may be seen by the general public. The pictures, videos and text may also appear on other websites or in print, may be translated into other languages or used for commercial purposes. I have been offered the opportunity to read the manuscript.

3. Availability of data and materials: The datasets used and/or analysed during the current study available from the corresponding author on reasonable request. I confirm that all methods were carried out in accordance with relevant guidelines and regulations.

4. Competing interests: The author Prof. Nicola Malizia declares not to have interests in conflict.

5. Funding: Personal funds of Professor Nicola Malizia. 
6. Authors' contributions: NM had entirely prepared all the parts that make up the research article, including the figures (1-2-3-4-5) and tables (1-2-3-). NM had only been supported in the data collection phase by the research group on "deviance and crime" of the Kore University of Enna (Italy).

7. Acknowledgements: I would like to thank the research group on "deviance and crime" of the University of Enna "Kore" - Italy, consisting of young researchers and graduates, for the commitment shown in all phases of research and without which it would not have been possible to achieve the results presented.

\section{References}

[1] Barbalet JM. Boredom and Social Meaning. British Journal of Sociology 1999; 50:631-646. https://doi.org/10.1080/000713199358572

[2] Beck KH, Caldeira KM, Vincent KB, et al. "The social context of cannabis use: Relationship to cannabis use disorders and depressive symptoms among college students", Addictive Behaviors. 2009; 34: 764768. doi:10.1016/j.addbeh.2009.05.001

[3] Bränström R, Pachankis, JE. Sexual orientation disparities in the co-occurrence of substance use and psychological distress: A national population-based study (2008-2015). Social Psychiatry and Psychiatric Epidemiology: The International Journal for Research in Social and Genetic Epidemiology and Mental Health Services. 2018; 53(4): 403-412. https://doi.org/10.1007/s00127-018-1491-4.

[4] Brissett D, Snow RP. Boredom: Where the Future Isn't. Symbolic Interaction. 1993; 16: 237-256. https://doi.org/10.1525/si.1993.16.3.237

[5] Burton R, Sheron N. No level of alcohol consumption improves health. Lancet. 2018; Sep 22;392(10152): 987-988. doi: 10.1016/S0140-6736(18)31571-X.

[6] Calamai G. Substance use and abuse. Understanding and coping with alcohol and drug addictions. Trento (Italy): Erickson 2018.

[7] Cao W, Fang Z, Hou G, et al. The psychological impact of the COVID-19 epidemic on college students in China, Psychiatry Research. 2020; 287.

https://doi.org/10.1016/j.psychres.2020.112934.

[8] Censi V, Padrevecchi F, Salvador E. Alcohol abuse. When drinking drowns feeling. Milano (Italy): Hoeply 2019.

[9] Corbin WR, Hartman JD, Curlee AS, et al. The Role of Relationship Changes in College Students Heavy Episodic Drinking. Alcohol Clin Exp Res 2020; 44: 1273-1283. https://doi.org/10.1111/acer.14347 
[10] Galea S, Merchant RM, Lurie N. (2020). The mental health consequences of COVID-19 and physical distancing: The need for prevention and early intervention. JAMA Internal Medicine. 2020: 180(6): 817818. https://doi.org/10.1001/jamainternmed.2020.1562.

[11] Giddens A. Modernity and Self-Identity. Palo Alto, CA: Stanford University Press 1991.

[12] Goffman E. Stigma, Denied identity. Verona (Italy) Ombre Corte 1963.

[13] Hassel A, Nordfjaern T, Hagen R. Psychological and interpersonal distress among patients with substance use disorders: Are these factors associated with continued drug use and do they change during treatment. Journal of Substance Use. 2013; 18(5): 363-376.

[14] Iso-Ahola SE, Crowley BD. Adolescent Substance Abuse and Leisure Boredom. Journal of Leisure Research. 1991; 23: 260-271.

[15] Li S, Wang Y, Xue J, et al. The Impact of COVID-19 Epidemic Declaration on Psychological Consequences: A Study on Active Weibo Users. Int. J. Environ. Res. Public Health. 2020; 17, 2032. https://doi.org/10.3390/ijerph17062032.

[16] Lin SY, Fried El, Eaton NR. The association of life stress with substance use symptoms: A network analysis and replication. Journal of Abnormal Psychology. 2020; 129(2): 204-214.

[17] Lyers M, Cutinho D, Thorberg FA. Alexithymia, impulsivity, disordered social media use, mood and alcohol use in relation to Facebook self-disclosure. Computers in Human Behavior. 2020; (103): 174-180.

[18] Martin K, Impact of COVID-19 on retail alcohol sales. Found on the World Wide Web (2020): https://www.winsightgrocerybusiness.com/center-store/impact-covid-19-retail-alcohol-sales.

[19] McIntyre RS, Lee Y. Preventing suicide in the context of the COVID-19 pandemic. World Psychiatry. 2020;19(2):250-251. doi: 10.1002/wps.20767.

[20] National Institute of Drug Abuse (NIDA) (2019). National survey on drug use and health: Trends in prevalence of various drugs for ages 12 or older, ages 12 to 17 , ages 18 to 25 , and ages 26 or older; 2016-2018 (in percent). As found on the World Wide Web: https://www.drugabuse.gov/drugtopics/trends-statistics/national-drug-early-warning-system-ndews/national-survey-drug-use-health.

[21] Orgilés M, Morales, A, Delvecchio, E, et al. (2020, April 21). Immediate psychological effects of the COVID-19 quarantine in youth from Italy and Spain. ( pre-print) https://doi.org/10.31234/osf.io/5bpfz

[22] Ornell F, Ferreira Moura H, Nichterwitz Scherer J, et al. The COVID-19 pandemic and its impact on substance use: Implications for prevention and treatment. Psychiatry Research. 2020; 289, 113096.

[23] Panagiotidis P, Rantis K, Holeva V, Parlapani E, et al. Changes in Alcohol Use Habits in the General Population, during the COVID-19 Lockdown in Greece. Alcohol and Alcholism (Oxford, Oxfordshire). 2020; 
55 (6): 702-704. https://doi.org/10.1093/alcalc/agaa092.

[24] Qiu J, Shen B, Zhao M, et al. . A nationwide survey of psychological distress among Chinese people in the COVID-19 epidemic: implications and policy recommendations. Gen Psychiatr. 2020; 27; 33(2): e100213corr1.

[25] Sargent JD, Cukier S, Babor Tf . Alcohol Marketing and Youth Drinking: Is There a Causal Relationship, and Why Does It Matter? Journal of Studies on Alcohol and Drugs. 2020; s19: 5-12.

[26] Scott S, Muir C, Stead M, et al. Exploring the links between unhealthy eating behaviour and heavy alcohol use in the social, emotional and cultural lives of young adults (aged 18-25): A qualitative research study. Appetite. 2020; 144. https://doi.org/10.1016/j.appet.2019.104449.

[27] Sola V, Sakiyama HMT, Rato Padin MDF, Canfield M, et al. Measuring stress, coping, strain, and hopefulness of Brazilian family members of substance misusers: Factor structure of a set of measures. Journal of Substance Use. 2019; 24(2): 130-139.

[28] Stebbin RA. Choice in Experiential Definitions of Leisure. Leisure Studies Association Newsletter, 2002; 63: 18-20.

[29] Substance Abuse and Mental Health Services Administration (SAMHSA) (2020). Substance use disorder treatment for people with co-occurring disorders. US Department of Health and Human Services, https://store.samhsa.gov/product/tip-42-substance-use-treatment-persons-co-occurring-disorders/PEP2002-01-004.

[30] Thomas W. I., The Unadjusted Girl. Boston: Little Brown, 1923.

[31] Volkart H. Social Behavior and Personality. Contributions of W.I. Thomas to Theory and Social Research, New York, NY: Social Science Research Council 1951.

[32] Walker DD, Jaffe AE, Pierce AR, et al. Discussing substance use with clients during the COVID-19 pandemic: A motivational interviewing approach. Psychological Trauma Theory Research Practice and Policy. 2020; 12(S1: S115-S117.

[33] Zuckerman M, Eysenck SB, Eysenck HJ. Sensation Seeking in England and America: Cross-Cultural, Age, and Sex Comparisons. Journal of Consulting and Clinical Psychology. 1978; 46: 139-149. https://doi.org/10.1037/0022-006X.46.1.139

\section{Figures}




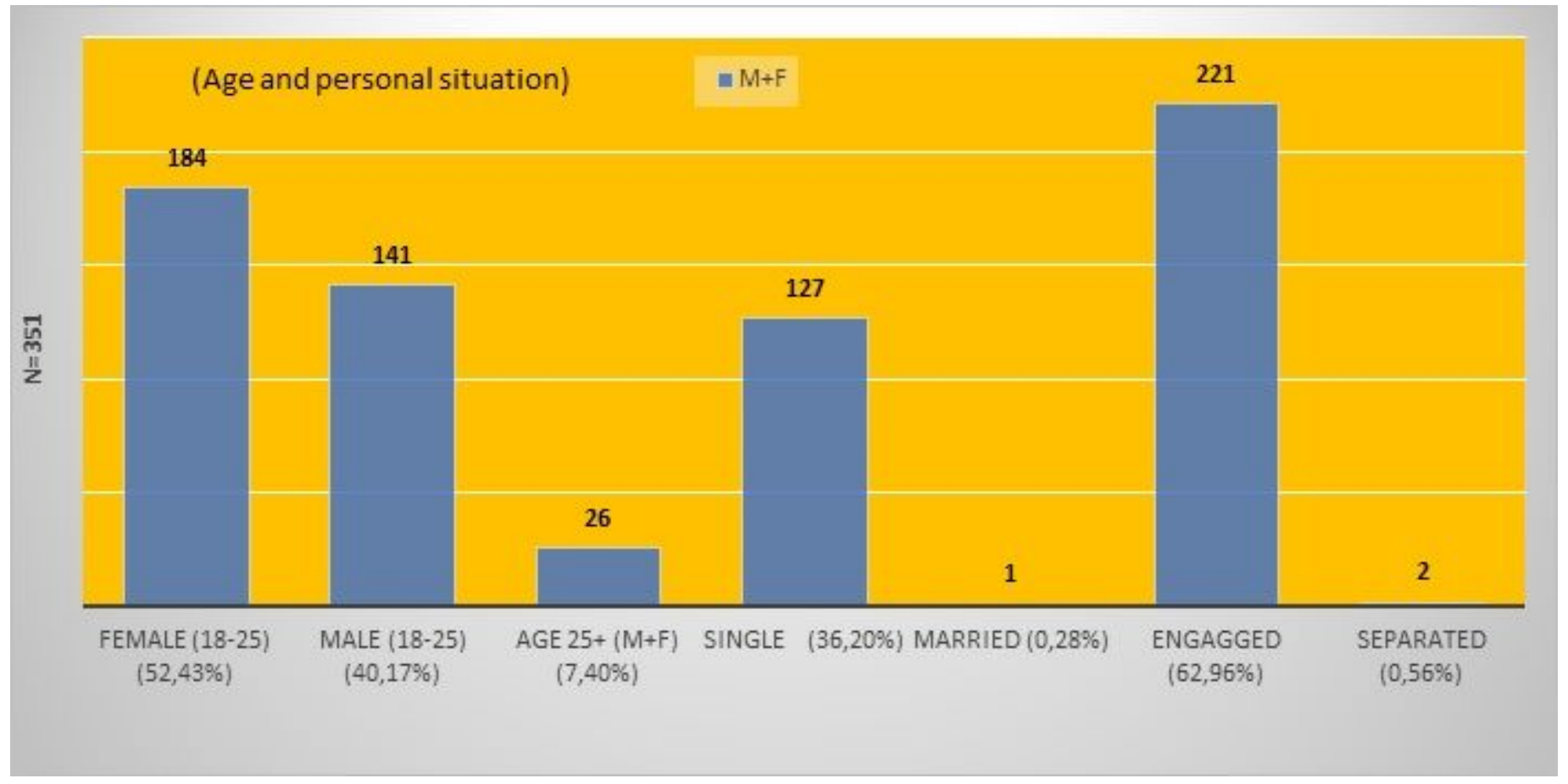

\section{Figure 1}

Individual data. Italian university students sample (alcohol during Covid-19 year 2020) (N=351)
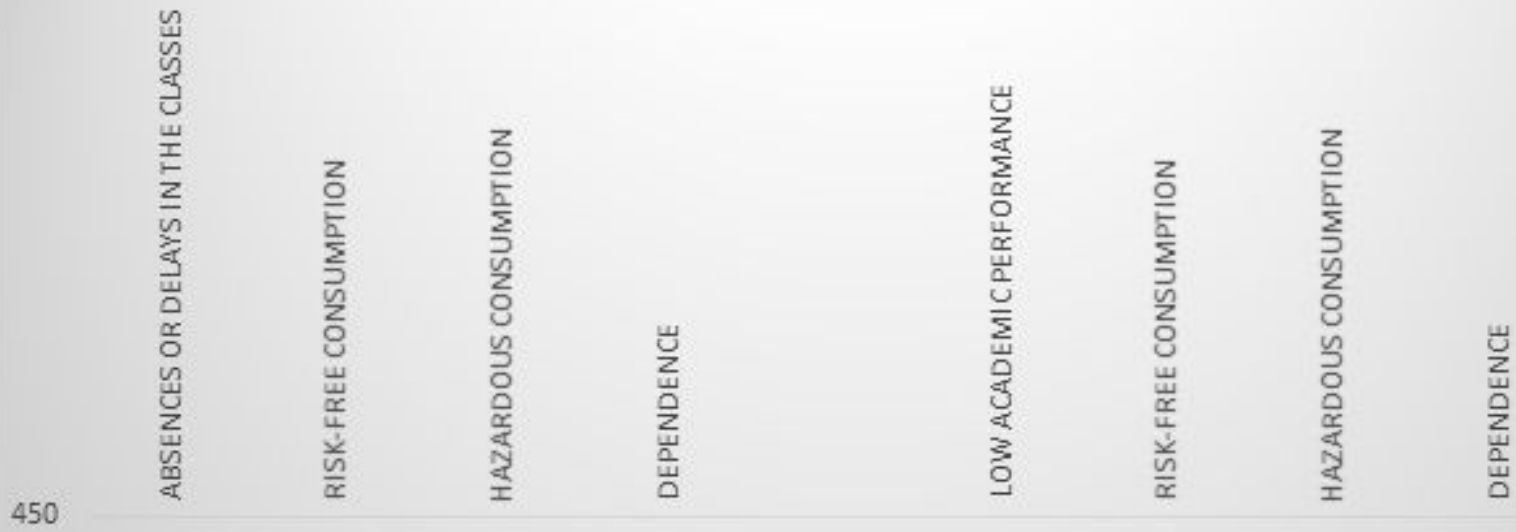

400

350

300

250

200

150

100

50

0
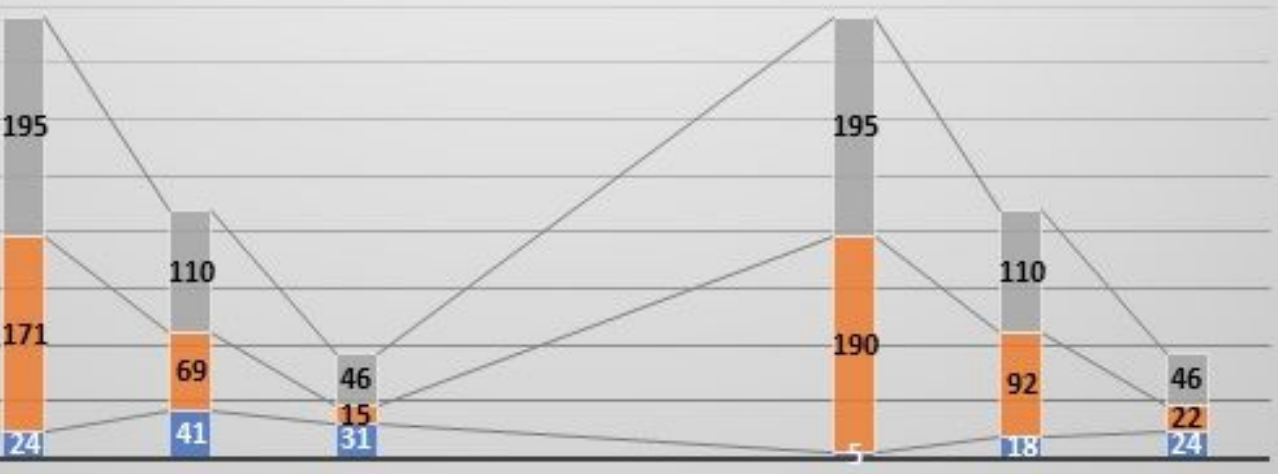

Absences or delays in the classes: P value $\leq 0.001$; Low Academic performance: P value 50.001

Figure 2 
Academic problems and their correlation with the AUDIT. Alcohol consumption and related problems in university students, during Covid-19. Italy ( $\mathrm{N}=351)$

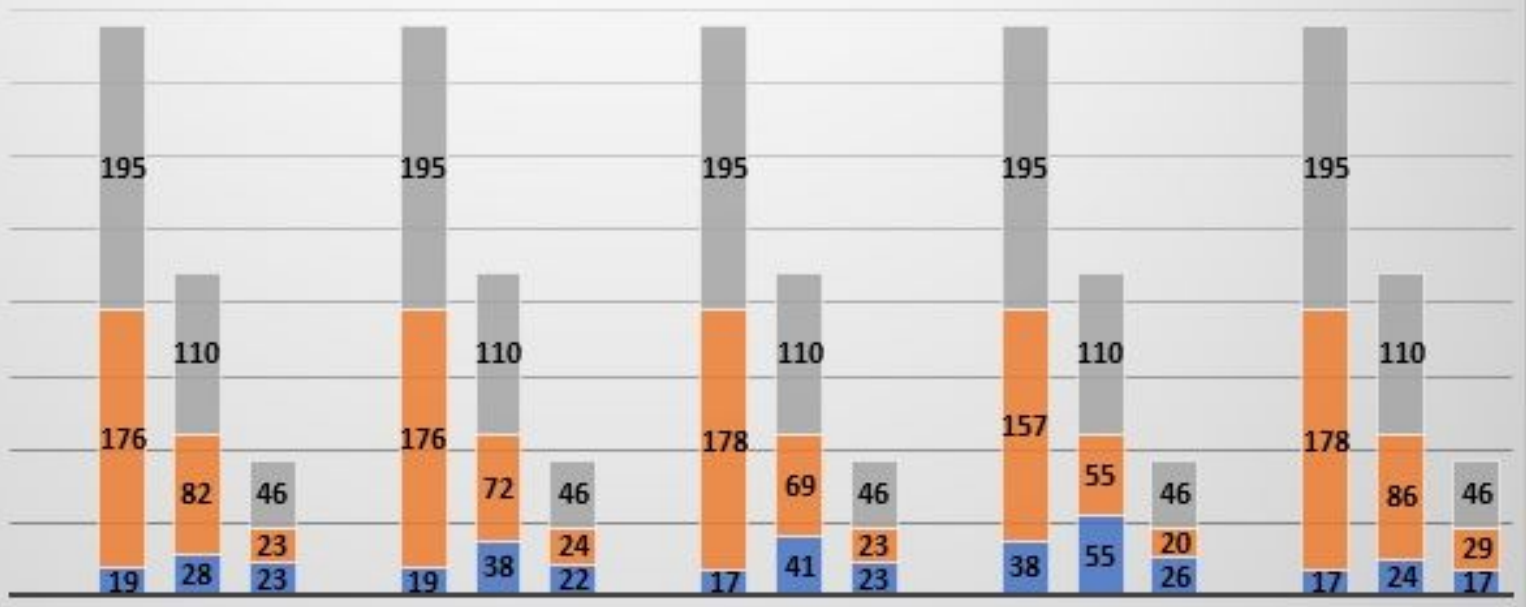

Conflict with prents: P value $\leq 0.001$

Depression: $\mathrm{P}$ value $\leq 0.001$

Anxiety: $P$ value $\leq 0.001$

Emocional oscillation $P$ value $\leq 0.001$

Intitability, low tolerance: $P$ value $\leq 0.001$

- Yes 1 No - Total

\section{Figure 3}

Psychological problems and their correlation with the AUDIT, in italian university students, during Covid19 , year 2020 


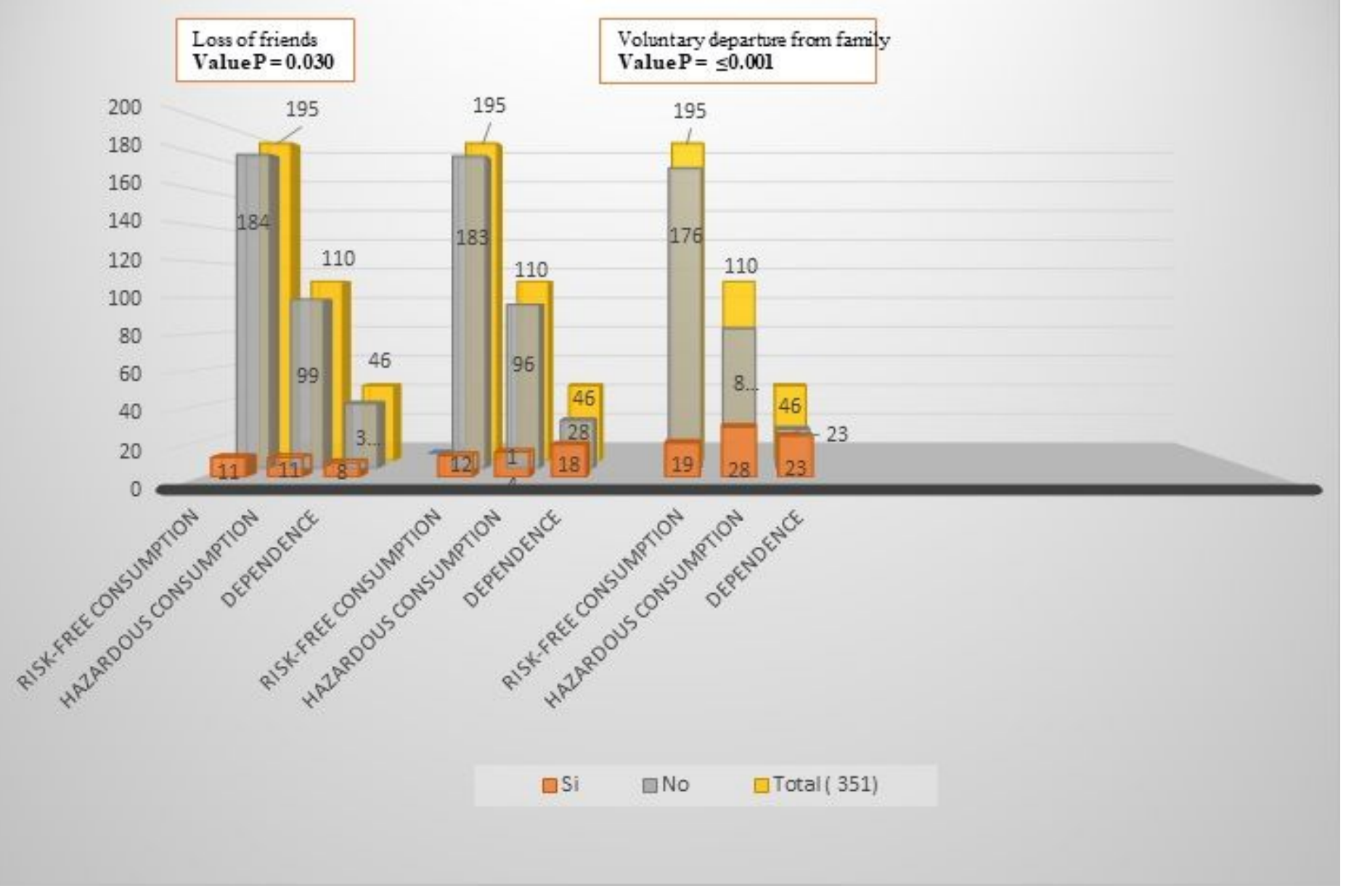

\section{Figure 4}

Social and family problems and their correlation with the AUDIT, in italian university students, during Covid-19, year 2020.

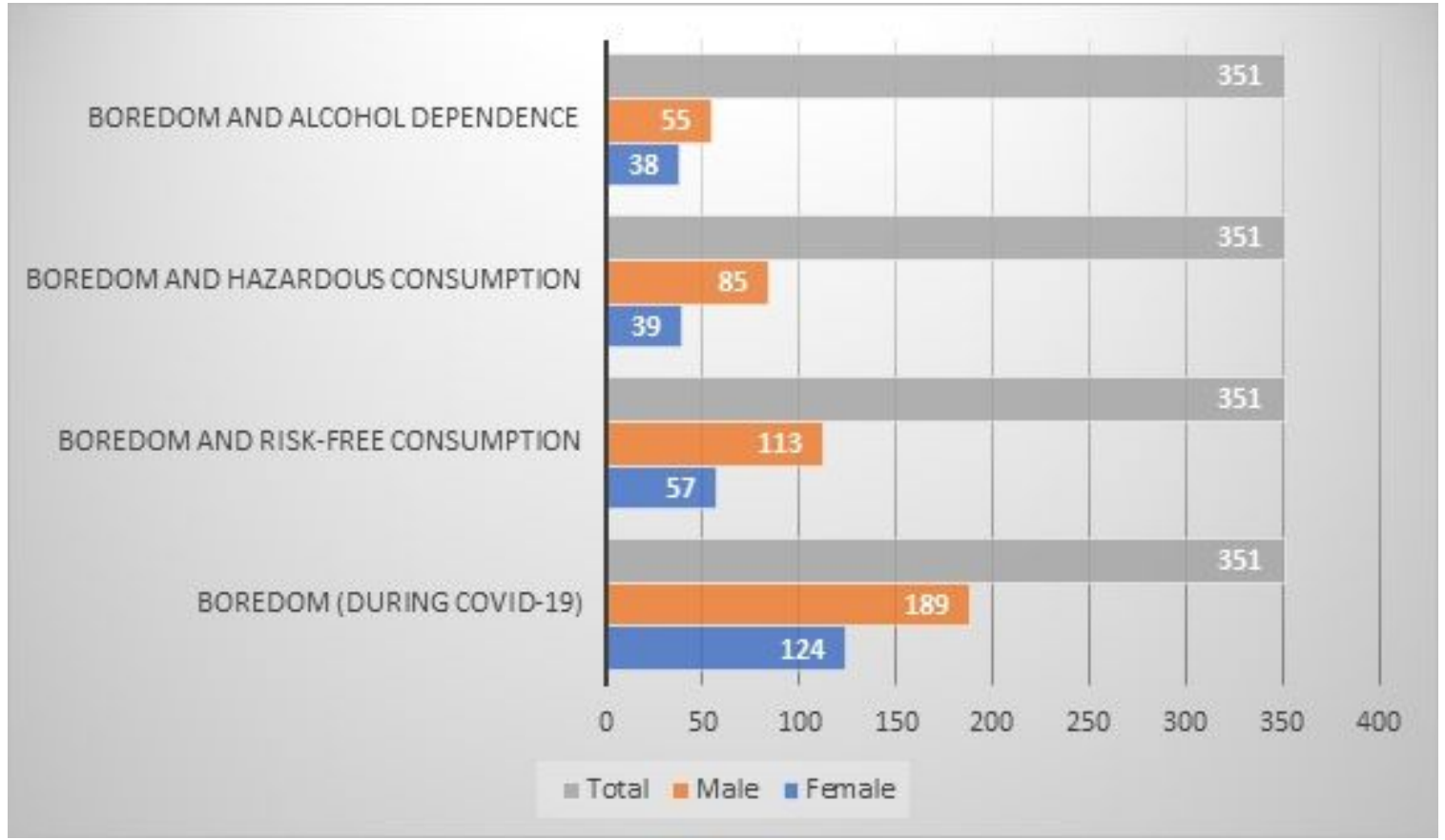


Figure 5

Boredom in italian university students during Covid-19 in correlation with AUDIT year 2020. 